\title{
Article \\ Effect of Impurities Control on the Crystallization and Densification of Polymer-Derived SiC Fibers
}

\author{
Young-jun Joo ${ }^{1}$, Sang-hyun Joo ${ }^{1}$, Hyuk-jun Lee ${ }^{1,2}$, Young-jin Shim ${ }^{1}$, Dong-geun Shin ${ }^{1}$ and Kwang-youn Cho ${ }^{1, *}$ \\ 1 Fibrous Ceramics \& Aerospace Materials Center, Korea Institute of Ceramic Engineering and Technology, \\ Jinju 52858, Korea; kicet_joo@kicet.re.kr (Y.-j.J.); judy@kicet.re.kr (S.-h.J.); kyg325@naver.com (H.-j.L.); \\ sksms182@naver.com (Y.-j.S.); dgshin73@kicet.re.kr (D.-g.S.) \\ 2 Division of Nano \& Advanced Materials Engineering, Gyeongsang National University, Jinju 52858, Korea \\ * Correspondence: kycho@kicet.re.kr; Tel.: +82-55-792-2710
}

check for updates

Citation: Joo, Y.-j.; Joo, S.-h.; Lee, H.-j.; Shim, Y.-j.; Shin, D.-g.; Cho, K.-y. Effect of Impurities Control on the Crystallization and Densification of Polymer-Derived SiC Fibers. Nanomaterials 2021, 11, 2933. https:// doi.org/10.3390/nano11112933

Academic Editor: Takuya Kitaoka

Received: 9 October 2021

Accepted: 31 October 2021

Published: 2 November 2021

Publisher's Note: MDPI stays neutral with regard to jurisdictional claims in published maps and institutional affiliations.

\begin{abstract}
The polymer-derived SiC fibers are mainly used as reinforcing materials for ceramic matrix composites (CMCs) because of their excellent mechanical properties at high temperature. However, decomposition reactions such as release of $\mathrm{SiO}$ and $\mathrm{CO}$ gases and the formation of pores proceed above $1400^{\circ} \mathrm{C}$ because of impurities introduced during the curing process. In this study, polycrystalline $\mathrm{SiC}$ fibers were fabricated by applying iodine-curing method and using controlled pyrolysis conditions to investigate crystallization and densification behavior. Oxygen and iodine impurities in amorphous $\mathrm{SiC}$ fibers were reduced without pores by diffusion and release to the fiber surface depending on the pyrolysis time. In addition, the reduction of the impurity content had a positive effect on the densification and crystallization of polymer-derived $\mathrm{SiC}$ fibers without a sintering aid above the sintering temperature. Consequently, dense Si-Al-C-O polycrystalline fibers containing $\beta$-SiC crystal grains of 50 100 nm were easily fabricated through the blending method and controlled pyrolysis conditions.
\end{abstract}

Keywords: polycarbonsilane; SiC fiber; impurities control; crystallization; densification

\section{Introduction}

Silicon carbide $(\mathrm{SiC})$ fiber with excellent oxidation resistance, high tensile strength, elastic modulus at high temperature is mainly used as a reinforcing material for ceramic matrix composites (CMCs) [1-3]. SiC fibers are generally manufactured by the processes of meltspinning, curing, and pyrolysis using polycarbosilane (PCS) as a ceramic precursor $[4,5]$. Especially, the polymer-derived $\mathrm{SiC}$ fibers can be largely divided into amorphous $\mathrm{SiC}$ fibers and polycrystalline $\mathrm{SiC}$ fibers depending on the oxidation resistance temperature, and various manufacturing methods have been studied to fabricate high-performance polycrystalline $\mathrm{SiC}$ fibers [6,7].

The curing methods essential for conversion from polymer fiber to ceramic fiber are classified into oxidation curing method [8-10], electron beam (EB) curing method [11-13], and chemical vapor curing (CVC) method [14-16], respectively. The oxidation curing method, which forms cross-linking such as Si-O-Si and Si-O-C bonds between PCS structures by reaction of PCS and hot air, is an inexpensive and easy method. However, oxygen as a cross-linker reduces the heat resistance of $\mathrm{SiC}$ fibers and causes problems in fabricating dense and polycrystalline $\mathrm{SiC}$ fibers.

The EB curing method was developed to manufacture high-heat resistant $\mathrm{SiC}$ fibers through the curing process without oxygen. The EB-cured PCS fibers are relatively easily converted into polycrystalline $\mathrm{SiC}$ fibers above $1500^{\circ} \mathrm{C}$ through the formation of radical bonds such as Si-Si and Si-C under a strong electron beam. However, the EB curing method is expensive and difficult to access in various industries because the EB irradiation equipment is very sophisticated and high power. 
Among CVC methods, the iodine curing method induces the oxidation reaction of PCS at $120^{\circ} \mathrm{C}$ or less, so it has the advantage of being applicable to low-melting point or low-molecular weight PCS. However, the amorphous SiC fiber fabricated by the iodine curing method contains iodine impurity as a cross-linking accelerator and oxygen impurity as a cross-linking agent. As a result, this amorphous SiC fiber not only has lower hightemperature heat resistance but is also difficult to convert to polycrystalline $\mathrm{SiC}$ fibers.

As mentioned above, it is known that amorphous $\mathrm{SiC}$ fibers fabricated by oxidation curing and CVC methods contain oxygen impurity in the vicinity of $10 \%[10,17]$. In amorphous $\mathrm{SiC}$ fibers, oxygen impurities exist in oxygen compounds such as the $\mathrm{SiO}_{\mathrm{x}} \mathrm{C}_{\mathrm{y}}$ and $\mathrm{SiO}_{2}$ phase and are decomposed into $\mathrm{SiO}$ and $\mathrm{CO}$ gases at high temperatures $\left(\geq 1300^{\circ} \mathrm{C}\right)[18,19]$. Consequently, it means that oxygen introduced as a cross-linking agent reduces the heat resistance of amorphous $\mathrm{SiC}$ fibers and prohibits conversion to polycrystalline $\mathrm{SiC}$ fibers with high-heat resistance. In this paper, iodine-cured PCS fibers were converted into amorphous $\mathrm{SiC}$ fibers via applying a controlled pyrolysis process, and then the crystallization behavior was investigated using amorphous $\mathrm{SiC}$ fiber with controlled oxygen content.

PCS containing various organometallic compounds have been synthesized to fabricate polycrystalline $\mathrm{SiC}$ fibers by inhibiting the decomposition of oxygen impurities during the conversion from amorphous $\mathrm{SiC}$ to crystalline $\mathrm{SiC}[20,21]$. In particular, $\mathrm{Si}-\mathrm{Al}-\mathrm{C}-\mathrm{O}$ fibers manufactured using polyaluminocarbosilane (PACS) are representative ceramic grade fibers having a strength retention temperature of $1700{ }^{\circ} \mathrm{C}[21,22]$. These modified PCS are usually synthesized using an autoclave or reflux system, but it is known that the blend method is good for mass production and easy application.

Therefore, in this work, amorphous $\mathrm{SiC}$ fibers without sintering aid were fabricated using the iodine curing method and controlled pyrolysis conditions, and then pyrolyzed at 1600 and $1800{ }^{\circ} \mathrm{C}$ to investigate the crystallization behavior of the polymer-derived $\mathrm{SiC}$ fibers. As a result, the amorphous $\mathrm{SiC}$ fibers prepared through the novel process of impurities control were converted into dense $\mathrm{SiC}$ polycrystalline fiber without additives such as sintering aids. In addition, Al-added PCS was easily prepared by the solution blend method, and dense Si-Al-C-O polycrystalline fibers were successfully fabricated by applying the crystallization behavior of $\mathrm{SiC}$ fibers investigated in this study.

\section{Experimental Procedure}

\subsection{Raw Materials}

Polycarbosilane (PCS) having weight average molecular weight $\left(\mathrm{M}_{\mathrm{w}}\right)$ of 3327 , number average molecular weight $\left(\mathrm{M}_{\mathrm{n}}\right)$ of 1565 , and melting point of $185^{\circ} \mathrm{C}$, respectively, was purchased from ToBeMTech Co., Ltd. (Yongin-si, Gyeonggi-do, Korea). Iodine (extra pure $99.0 \%$ ) as a cross-linking accelerator was purchased from Samchun pure chemical Co., Ltd. (Gangnam-gu, Seoul, Korea). Aluminum acetylacetonate (anhydrous 99.0\%) and toluene (anhydrous 99.7\%) were purchased from Sigma-Aldrich Inc. (Burlington, MA, USA).

\subsection{Preparation of Polycrystalline SiC Fibers}

PCS was melted at $180-190^{\circ} \mathrm{C}$ for $3 \mathrm{~h}$ in $\mathrm{N}_{2}$ atmosphere using single-hole spinning machine (DAEHO I\&T Co., Ltd., Jinju-si, Gyeongsangnam-do, Korea), as shown in Figure 1. Subsequently, PCS green fibers with a diameter of about $20 \mu \mathrm{m}$ were prepared through a winder speed of $1000 \mathrm{rpm}$. The chemical vapor curing method using iodine was adopted to fabricate the infusible PCS fiber because of the relatively low-melting point of PCS. The PCS green fiber and iodine in a weight ratio of 1:1 were placed together in a graphite mold, and then heat-treated up to $180^{\circ} \mathrm{C}$ at a heating rate of $10^{\circ} \mathrm{C} / \mathrm{min}$ in low vacuum. PCS green fibers were converted into cured PCS fibers with a bright yellow by reaction with iodine. To control the content of oxygen impurities during the pyrolysis process, the iodine-cured PCS fibers were heat-treated at $1400{ }^{\circ} \mathrm{C}$ for 2,4 , and $6 \mathrm{~h}$ in an inert atmosphere. Finally, the amorphous $\mathrm{SiC}$ fibers were heat-treated at $1800{ }^{\circ} \mathrm{C}$ in an inert atmosphere to analyze the crystallization behavior according to the oxygen impurity content. 


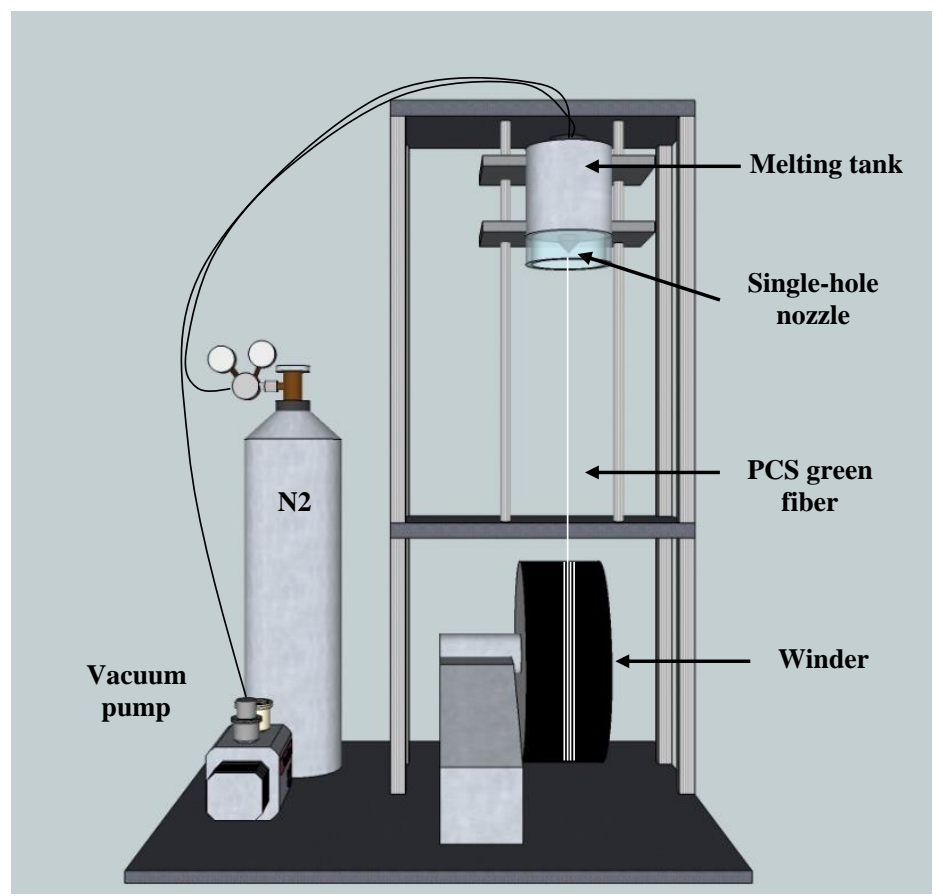

Figure 1. The schematic drawing of melt-spinning machine equipped with a single-hole nozzle.

\subsection{Preparation of Polycrystalline Si-Al-C-O Fibers}

The PCS solution was prepared using toluene, and aluminum acetylacetonate in an amount of 1,3, and $5 \mathrm{wt} \%$ based on the weight of the PCS was added and stirred at room temperature for $6-12 \mathrm{~h}$. The Al-added PCS solutions were vacuum-dried in the range of $150-180{ }^{\circ} \mathrm{C}$. During the melt-spinning process, the unreacted Al source causes the problem in reducing the diameter of the fiber and making it continuous. Therefore, the Al-added PCS bulk was again dissolved using toluene, and then filtered using a filter paper with a $0.08 \mu \mathrm{m}$ particle. The Al-added PCS solution prepared by removing the unreacted $\mathrm{Al}$ source was vacuum-dried under the same conditions, and the modified PCSs were named PCS-Al1, PCS-Al3, and PCS-Al5, respectively. The amorphous and polycrystalline SiC fibers containing $\mathrm{Al}$ content fabricated using PCS-Al precursor in the same method as described above.

\subsection{Measurements}

Fourier-transform infrared spectroscopy (FT-IR, L1860116, PerkinElmer, Waltham, MA, USA) analysis was performed in the range of $450-4000 \mathrm{~cm}^{-1}$. The PCS and modified PCS were pulverized into powder and measured in attenuated total reflection (ATR) mode by 16-times scan.

Thermogravimetric analysis (TG, STA449 F3, NETZSCH, Gebrüder-Netzsch-Straße $19,95100 \mathrm{Selb}$, Germany) was conducted at the heating rate of $10^{\circ} \mathrm{C} / \mathrm{min}$ up to $1600{ }^{\circ} \mathrm{C}$ to confirm the decomposition behavior and ceramic yield. PCS of $10.0 \mathrm{mg}$ was placed in an alumina crucible and analyzed after stabilization for $30 \mathrm{~min}$.

The morphology and element distribution of polymer-derived $\mathrm{SiC}$ fibers were observed by field emission-scanning electron microscopy (FE-SEM, JSM-7610F, JEOL, Tokyo, Japan). Pt coating was performed using an ion coater for $70 \mathrm{~s}$. Energy dispersive spectroscopy (EDS) was measured by repeating 5-10 times after pulverizing polymer-derived $\mathrm{SiC}$ fibers into fine powder. The standard deviation for the element content measurements of $\mathrm{Si}, \mathrm{C}, \mathrm{O}$, and I were $4.81 \%, 3.95 \%, 2.06 \%$, and $0.01 \%$, respectively.

X-ray diffraction analysis (XRD, DMAX 2500, Rigaku, Akishima-shi, Tokyo, Japan) in the range of $20-80^{\circ}$ was conducted to analyze the phase and crystallinity of the amorphous 
and polycrystalline $\mathrm{SiC}$ fibers. The measurement was carried out by scanning at $8^{\circ}$ per minute in continuous mode.

The microstructural analysis of SiC-polycrystalline fibers was carried out by transmission electron microscopy (TEM, FEI Titan Themis Z, Thermo Fisher Scientific, Waltham, MA, USA). TEM analysis samples were prepared using focused ion beam (FIB, Helios G4 UC, Thermo Fisher Scientific, Thermo Fisher Scientific, Waltham, MA, USA).

\section{Results and Discussion}

\section{The Crystallization Behavior of Polymer-Derived SiC Fibers}

Figure 2 shows the decomposition behavior of raw PCS and iodine-cured PCS fiber up to $1600^{\circ} \mathrm{C}$. The weight loss of raw PCS started at about $250{ }^{\circ} \mathrm{C}$ and ended at about $800{ }^{\circ} \mathrm{C}$. On the other hand, the weight loss of iodine-cured PCS fibers started at about $400{ }^{\circ} \mathrm{C}$ as a result of the condensation and dehydrogenation reaction that occurred in the curing process. In addition, the ceramic yield of iodine-cured PCS fiber at $1000{ }^{\circ} \mathrm{C}$ was increased by about $25 \%$ compared that of raw PCS. However, the weight loss of about $14.54 \%$ was additionally formed in the range of $1400-1600{ }^{\circ} \mathrm{C}$ due to iodine and oxygen impurities introduced during the curing process. The amorphous $\mathrm{SiC}$ fibers were prepared by heat treatment in an inert atmosphere for 2, 4, and $6 \mathrm{~h}$ to control the decomposition occurring at $1400-1600{ }^{\circ} \mathrm{C}$.

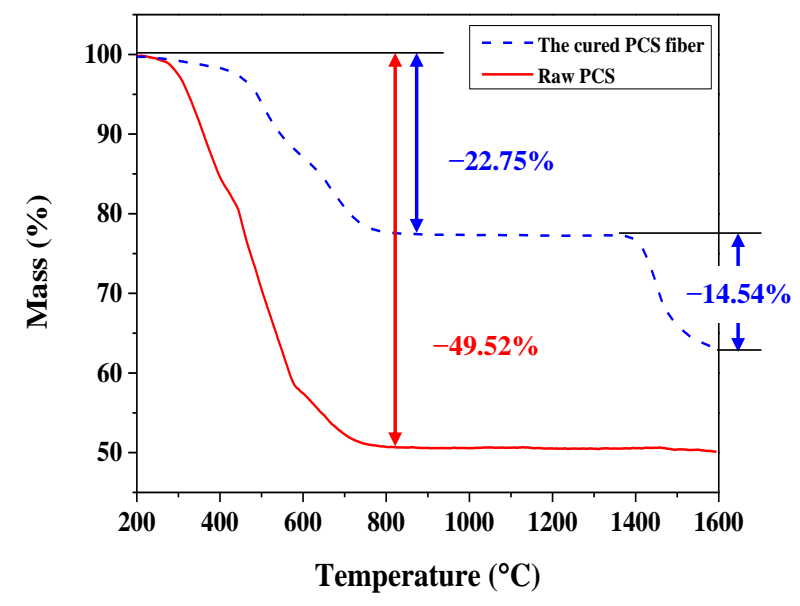

Figure 2. TG curves of raw PCS and iodine-cured PCS fibers.

Figure 3 shows the SEM-EDS results of amorphous SiC fibers depending on the heat treatment time. The polymer-derived $\mathrm{SiC}$ fibers fabricated at different times showed smooth cross-sectional surface without pores. However, the distribution of element content was changed according to the heat treatment time. $\mathrm{SiC}$ fibers fabricated through iodine curing method showed a lot of carbon and oxygen distribution on the surface. As the heat treatment time increased, the intensity of carbon and oxygen on the surface increased as the heat treatment time increased, but the distribution of silicon and iodine was maintained.

Table 1 exhibits the tendency of the element content in the amorphous SiC fiber prepared at different times. EDS mapping was performed on the pulverized powder to confirm the overall tendency. As a result, the iodine content introduced during the curing process was hardly observed in all samples, and the oxygen content decreased continuously with increasing pyrolysis time. These results indicated that the pyrolysis process at $1400{ }^{\circ} \mathrm{C}$ for a long-time has an effect on removal of impurities from the amorphous $\mathrm{SiC}$ fiber without pores or defects.

Figure 4 shows the $\mathrm{X}$-ray diffraction patterns of the polymer-derived $\mathrm{SiC}$ fibers. The three main peaks at $36^{\circ}, 41^{\circ}, 60^{\circ}, 70^{\circ}$, and $76^{\circ}$ correspond to the (111), (200), (220), (311), and (222) planes of the $\beta$-SiC crystal. The polymer-derived $\mathrm{SiC}$ fibers with different pyrolysis times showed broad peaks overall. In particular, it was observed that $\mathrm{SiC}$ fibers prepared at $1400{ }^{\circ} \mathrm{C}$ for $6 \mathrm{~h}$ exhibited a narrower full width at half maximum (FWHM) and 
additional crystal plane compared to fibers prepared at 2 and $4 \mathrm{~h}$ due to crystallization by decomposition of the $\mathrm{SiO}_{x} \mathrm{C}_{y}$ phase.
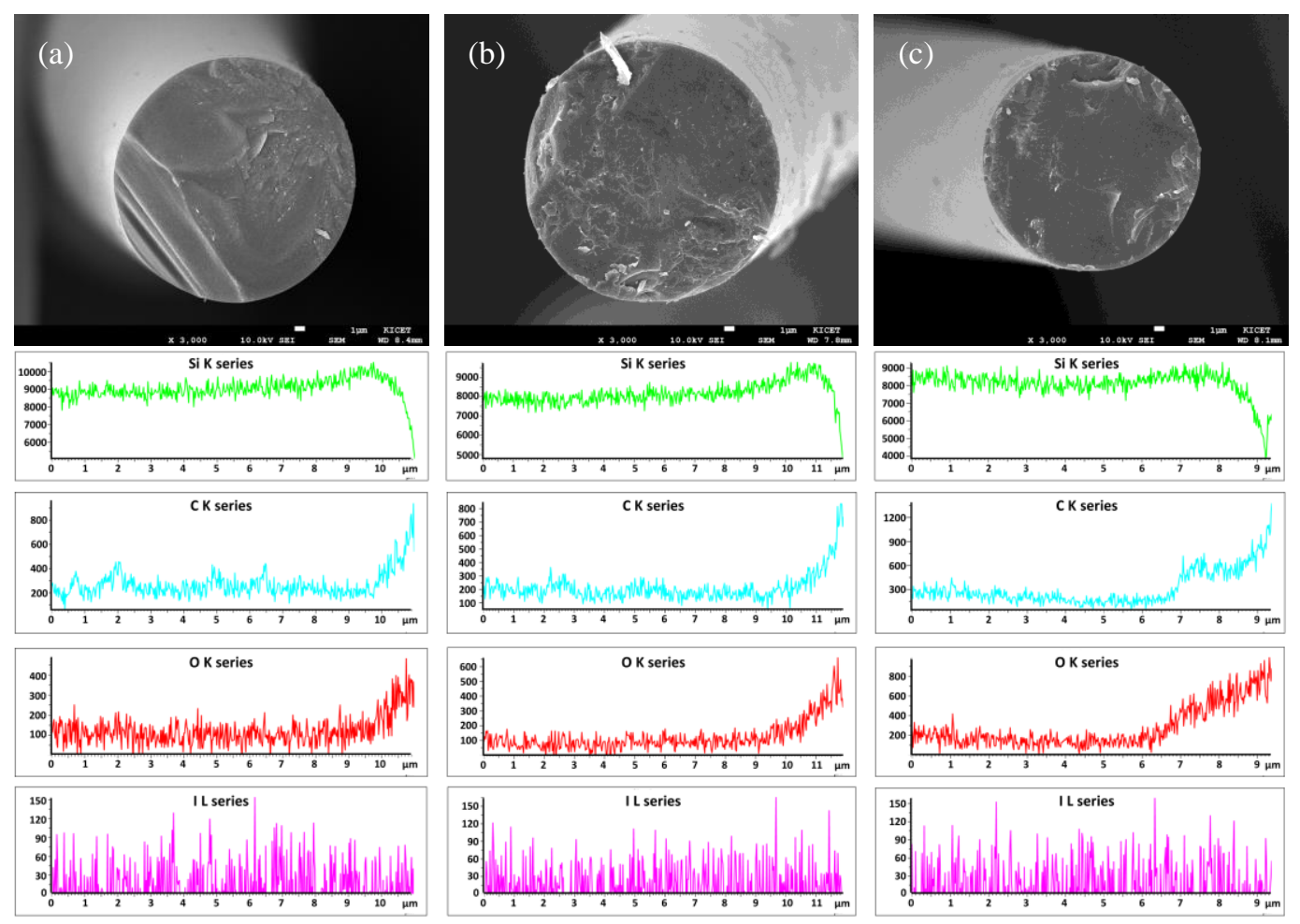

Figure 3. SEM-EDS images of the polymer-derived $\mathrm{SiC}$ fibers fabricated at $1400{ }^{\circ} \mathrm{C}$ for (a) 2 , (b) 4 , and (c) $6 \mathrm{~h}$.

Table 1. EDS mapping of amorphous SiC fiber depending on the heat treatment time.

\begin{tabular}{ccccccc}
\hline \multirow{2}{*}{ Elmt } & \multicolumn{2}{c}{$\mathbf{1 4 0 0 / 2}$} & \multicolumn{2}{c}{$\mathbf{1 4 0 0 / 4}$} & \multicolumn{2}{c}{$\mathbf{1 4 0 0 / 6}$} \\
\cline { 2 - 7 } & $\mathbf{w t} \%$ & $\mathbf{a t} \%$ & $\mathbf{w t} \%$ & $\mathbf{a t} \%$ & $\mathbf{w t} \%$ & $\mathbf{a t} \mathbf{0}$ \\
\hline $\mathrm{Si}$ & 45.62 & 27.39 & 44.96 & 26.64 & 48.03 & 29.14 \\
$\mathrm{C}$ & 45.27 & 63.20 & 48.52 & 66.69 & 46.04 & 64.68 \\
$\mathrm{O}$ & 9.02 & 9.39 & 6.42 & 6.66 & 5.88 & 6.18 \\
$\mathrm{I}$ & 0.09 & 0.01 & 0.01 & 0.01 & 0.04 & 0.01 \\
C/Si ratio & - & 2.31 & - & 2.50 & - & 2.21 \\
\hline
\end{tabular}

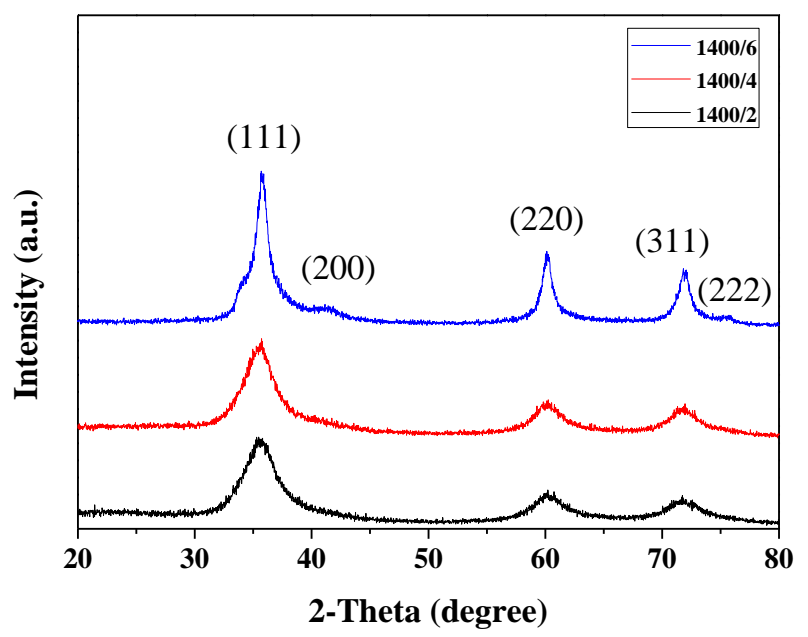

Figure 4. X-ray diffraction patterns of the polymer-derived $\mathrm{SiC}$ fiber with different heat treatment times. 
Figure 5a-c shows SEM images of polymer-derived SiC fibers fabricated at $1800{ }^{\circ} \mathrm{C}$ without impurity control process. Additionally, Figure $5 \mathrm{~d}-\mathrm{f}$ shows the dense polymerderived $\mathrm{SiC}$ fiber fabricated by heat treatment at $1800^{\circ} \mathrm{C}$ again after controlling the impurity contents at $1400{ }^{\circ} \mathrm{C}$ for $6 \mathrm{~h}$. The polymer-derived $\mathrm{SiC}$ fiber in Figure $5 \mathrm{a}, \mathrm{b}$ had a porous layer of about $4.9 \mu \mathrm{m}$ and large $\mathrm{SiC}$ crystals on the surface compared with that of Figure $5 \mathrm{~d}$,e. On the other hand, the core region of the SiC fiber had a very dense surface and similar grain size as shown in Figure 5 c,f. These results showed that impurity control had a great effect on the uniform densification of $\mathrm{SiC}$ fibers and suppression of the formation of the large $\mathrm{SiC}$ crystals on the surface.
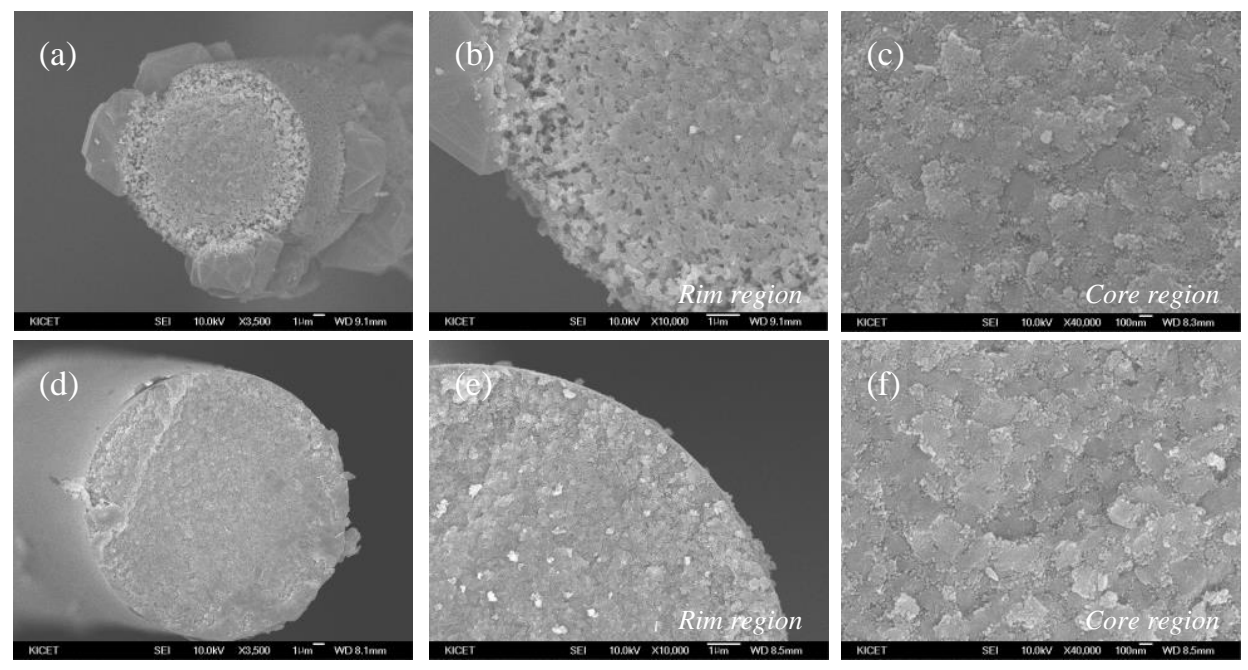

Figure 5. SEM images of polymer-derived SiC fibers fabricated at $1800{ }^{\circ} \mathrm{C}$ with $(\mathbf{a}-\mathbf{c})$ uncontrolled and $(\mathbf{d}-\mathbf{f})$ controlled pyrolysis process.

Figure 6 shows the cross-sectional SEM images of the polycrystalline SiC fibers fabricated using the amorphous $\mathrm{SiC}$ fiber with controlled impurity content. The amorphous $\mathrm{SiC}$ fibers prepared by pyrolysis for 2,4 , and $6 \mathrm{~h}$ were additionally heat treatment at 1600 and $180{ }^{\circ} \mathrm{C}$ in an inert atmosphere to confirm the crystallization behavior. In the polycrystalline $\mathrm{SiC}$ fiber heat-treated at $1600{ }^{\circ} \mathrm{C}$, coarsening of crystal grains was observed on the fiber surface despite the use of amorphous $\mathrm{SiC}$ fiber with controlled oxygen content. On the other hand, the polycrystalline $\mathrm{SiC}$ fiber fabricated at $1800{ }^{\circ} \mathrm{C}$ showed a dense surface due to the control effect of the impurity content in the fabrication stage of amorphous $\mathrm{SiC}$ fibers.

As shown in Figure 3 and Table 1, the amorphous SiC fiber fabricated through iodine curing method showed decomposition by the release of residual iodine with $\mathrm{SiO}$ and $\mathrm{CO}$ gases above $1400{ }^{\circ} \mathrm{C}$ without pores. The surface of this fiber contains high oxygen and carbon contents compared to the inside. In fact, impurity gases that decompose in the vicinity of the surface can be easily released and removed during heat treatment, but the impurity gases generated in the core region diffused out to the surface, leaving large pores between the surface and the core [22,23].

For this reason, the polymer-derived $\mathrm{SiC}$ fibers fabricated below sintering temperature (at $1600^{\circ} \mathrm{C}$ ) showed dense core region and porous rim region despite the control of impurity contents due to the lower sintering temperature and residual impurities. On the other hand, above the sintering temperature (at $1800{ }^{\circ} \mathrm{C}$ ), the polymer-derived $\mathrm{SiC}$ fiber not only induced $\mathrm{SiC}$ crystal growth by reacting $\mathrm{SiO}$ gas, $\mathrm{SiO}_{2}$, and free carbon generated in the core region, but also filled the micropores formed in the decomposition temperature region by sintering as shown in Figure 6f. The crystallization and degradation behaviors of polymer-derived $\mathrm{SiC}$ fibers with controlled impurity content are summarized using SEM-EDS results in Figure 7. In other words, long-time heat treatment in the stage of amorphous $\mathrm{SiC}$ fiber means that it is possible to reduce the content of impurities and 
help in the manufacturing of polycrystalline $\mathrm{SiC}$ fibers without sintering aid when oxygen content is introduced by the curing process.
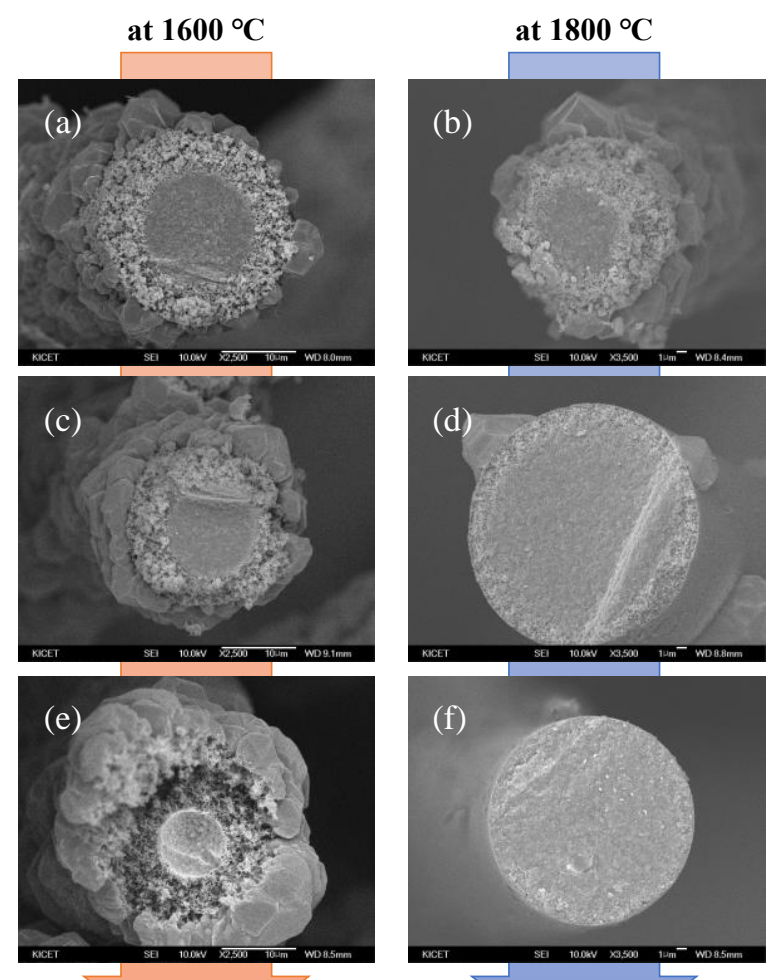

Decomposition

Densification

Figure 6. The cross-sectional SEM images of polycrystalline SiC fibers fabricated at 1600 and $1800{ }^{\circ} \mathrm{C}$ using fibers with controlled impurity content at $1400{ }^{\circ} \mathrm{C}$ for $(\mathbf{a}, \mathbf{b}) 2,(\mathbf{c}, \mathbf{d}) 4$, and (e,f) $6 \mathrm{~h}$.
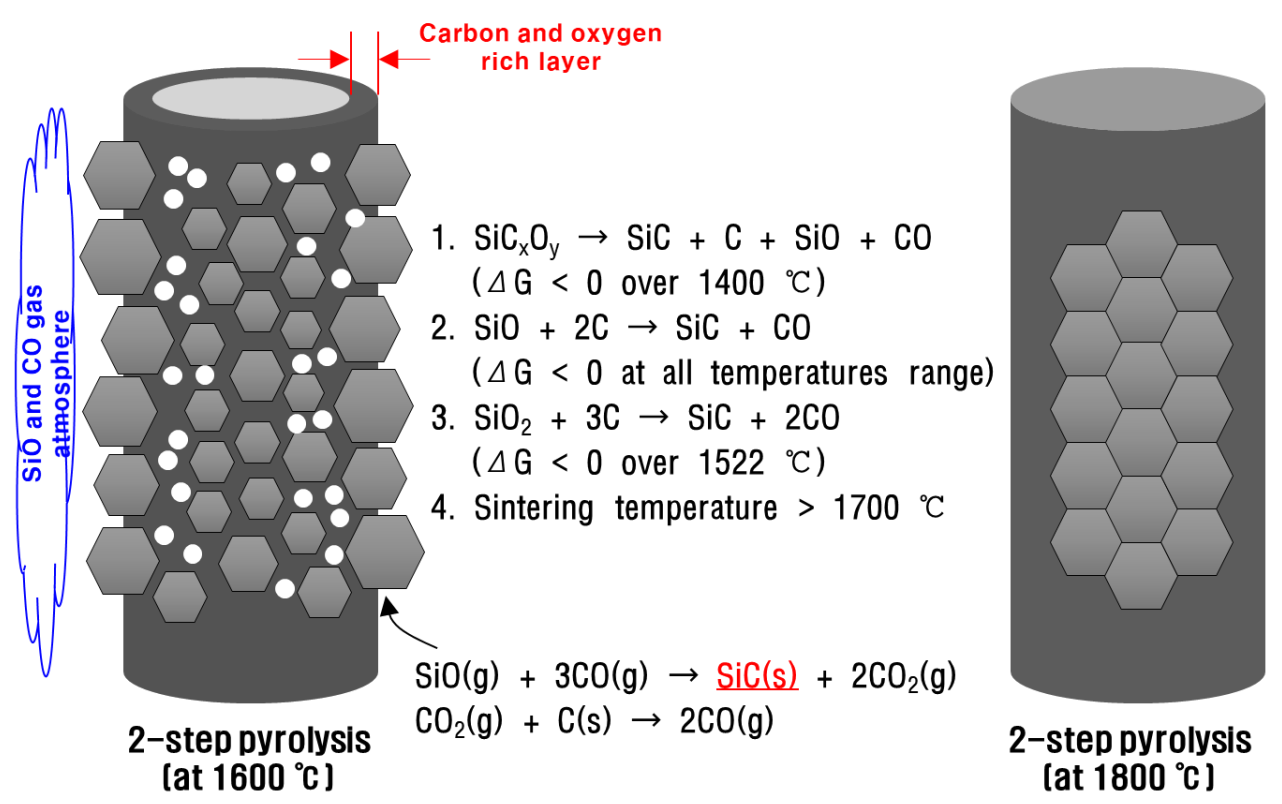

Figure 7. The schematic drawing of the crystallization behavior of polymer-derived SiC fibers.

Figure 8 shows the $\mathrm{X}$-ray diffraction patterns of amorphous $\mathrm{SiC}$ fibers and polycrystalline $\mathrm{SiC}$ fibers fabricated via the control of impurity contents. The polycrystalline $\mathrm{SiC}$ fibers fabricated at 1600 and $1800{ }^{\circ} \mathrm{C}$ showed sharp peaks at $36^{\circ}, 41^{\circ}, 60^{\circ}, 70^{\circ}$, and $76^{\circ}$ compared to those of amorphous $\mathrm{SiC}$ fibers. 


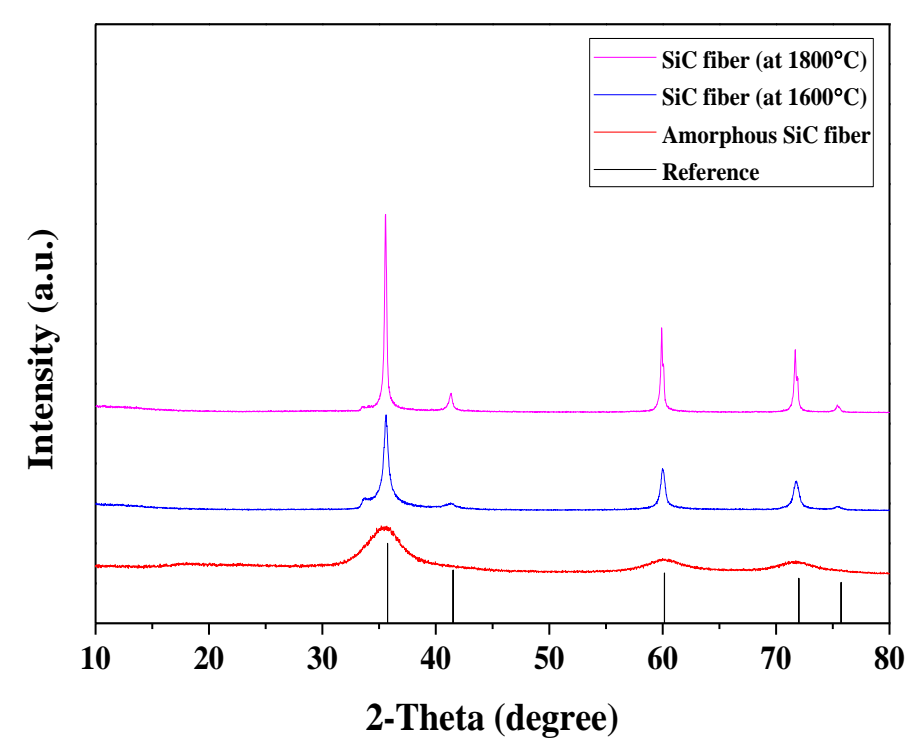

Figure 8. The schematic drawing of the crystallization behavior of polymer-derived SiC fibers.

PCS with aluminum source were prepared through the blend method, which is a method for easily reacting PCS with organometallic compounds. Al-added PCS fibers were heat-treated with iodine at a weight ratio of 1:1 in the same manner as described above. Then, polycrystalline Si-Al-C-O fibers were fabricated by pyrolyzing at 1400 and $1800{ }^{\circ} \mathrm{C}$ applying an impurity control process. Figure 9 shows a cross-sectional SEM image of polycrystalline Si-Al-C-O fibers. It was confirmed that the polycrystalline Si-Al-C-O fibers prepared through iodine curing had a very dense and clean surface due to the influence of $\mathrm{Al}$ as a sintering aid as well as a controlled heat treatment process.
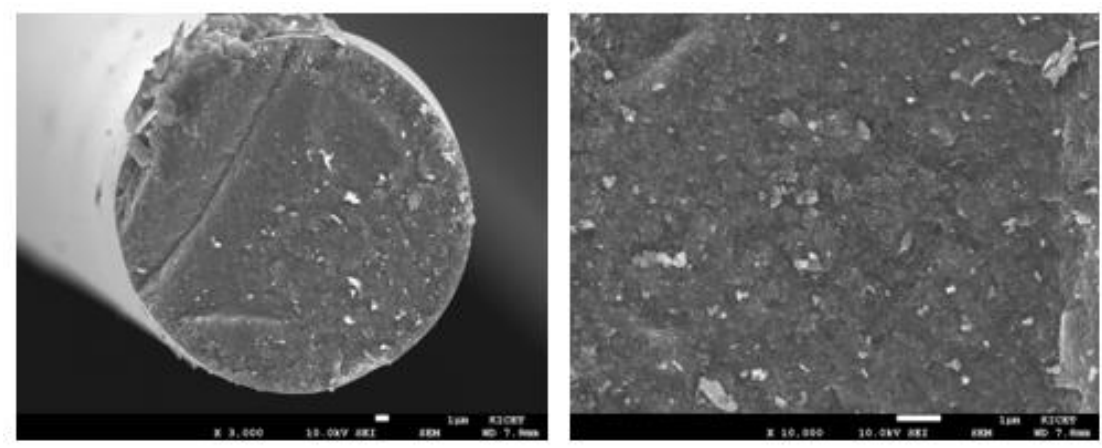

Figure 9. The cross-sectional SEM images of the polycrystalline Si-Al-C-O fibers fabricated via the control of impurity contents.

Figure 10 shows selected area diffraction (SAD) pattern and TEM images of polycrystalline $\mathrm{Si}-\mathrm{Al}-\mathrm{C}-\mathrm{O}$ fiber fabricated at $1800^{\circ} \mathrm{C}$ using controlled pyrolysis conditions. In Figure 10a, the SAD pattern showed a ring pattern similar to that of an amorphous $\mathrm{SiC}$ fiber because fine $\mathrm{SiC}$ crystal grains and free carbon were alternately stacked as shown in Figure $10 \mathrm{~b}$. In addition, Figure $10 \mathrm{~b}, \mathrm{c}$ shows polycrystalline $\mathrm{SiC}$ grains with a diameter of 50-100 nm. 

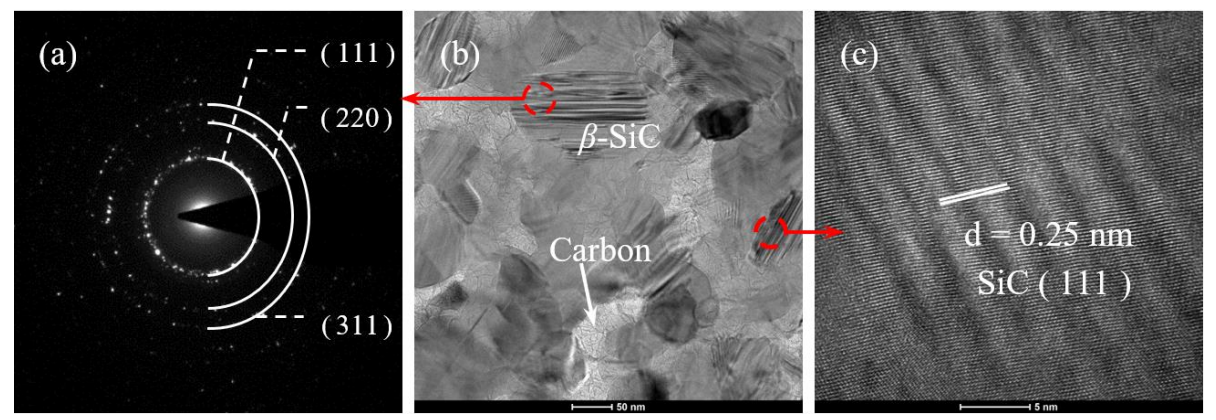

Figure 10. (a) SAD pattern and (b,c) TEM images of polycrystalline Si-Al-C-O fiber fabricated using the controlled pyrolysis condition.

\section{Conclusions}

In this work, the crystallization behavior of polymer-derived SiC fibers was investigated by applying controlled pyrolysis conditions without sintering aid. It was confirmed that oxygen and iodine impurities gradually decreased without defects by long-time pyrolysis conditions of the fiber to which iodine curing was applied. Additionally, $\mathrm{SiC}$ fibers fabricated at $1800{ }^{\circ} \mathrm{C}$ exhibited the release of $\mathrm{SiO}$ and $\mathrm{CO}$ gases to the surface and densification behavior from the inside during crystal growth of $\beta$-SiC. On the other hand, the polycrystalline $\mathrm{SiC}$ fiber fabricated at $1600{ }^{\circ} \mathrm{C}$ was not densified despite the use of amorphous $\mathrm{SiC}$ fibers with low-oxygen content. This meant that a specific temperature above the sintering temperature was required as well as a reduction in the content of oxygen impurities for dense $\mathrm{SiC}$-polycrystalline fibers. As a result, the polycrystalline $\mathrm{Si}-\mathrm{Al}-\mathrm{C}-\mathrm{O}$ fibers prepared using controlled pyrolysis conditions had a dense structure including fine crystal grains of $50-100 \mathrm{~nm}$.

Author Contributions: Supervision, K.-y.C.; Project administration, K.-y.C.; Writing—original draft \& review \& editing, Y.-j.J.; Resource, D.-g.S. and S.-h.J.; Data curation, Y.-j.J., S.-h.J., H.-j.L., Y.-j.S., and D.-g.S. All authors have read and agreed to the published version of the manuscript.

Funding: This research received no external funding.

Acknowledgments: This work was supported by the Industrial Strategic Technology Development Program funded by the Ministry of Trade, Industry \& Energy (MOTIE, Korea). [Program Name: Development of seminoncombustible protection product using economical $\mathrm{SiC}$ fiber mass production technology/Project Number: 1415172237].

Conflicts of Interest: The authors declare no conflict of interest.

\section{References}

1. Naslain, R. Design, preparation and properties of non-oxide CMCs for application in engines and nuclear reactors: An overview. Compos. Sci. Technol. 2004, 64, 155-170. [CrossRef]

2. Nasiri, N.A.; Patra, N.; Ni, N.; Jayaseelan, D.D.; Lee, W.E. Oxidation behaviour of SiC/SiC ceramic matrix composites in air. J. Eur. Ceram. Soc. 2016, 36, 3293-3302. [CrossRef]

3. Thornton, J.; Arhatari, B.D.; Sesso, M.; Wood, C.; Zonneveldt, M.; Kim, S.Y.; Kimpton, J.A.; Hall, C. Failure evaluation of a SiC/SiC ceramic matrix composite during in-situ loading using micro X-ray computed tomography. Microsc. Microanal. 2019, $25,583-591$. [CrossRef]

4. Yajima, S.; Hayashi, J.; Omuri, M.; Okamura, K. Development of a silicon carbide fibre with high tensile strength. Nature 1976, 261, 683-685. [CrossRef]

5. Yajima, S.; Hasegawa, Y.; Hayashi, J.; Iimura, M. Synthesis of continuous silicon carbide fibre with high tensile strength and high Young's modulus. Part 1 synthesis of polycarbosilane as precursor. J. Mater. Sci. 1978, 13, 2569-2576.

6. Ichikawa, H. Polymer-derived ceramic fibers. Annu. Rev. Mater. Res. 2016, 46, 335-356. [CrossRef]

7. Colombo, P.; Mera, G.; Riedel, R.; Sorarù, G.D. Polymer-derived ceramics: 40 Years of research and innovation in advanced ceramics. J. Am. Ceram. Soc. 2010, 93, 1805-1837. [CrossRef]

8. Ichikawa, H.; Machino, F.; Mitsuno, S.; Ishikawa, T.; Okamura, K.; Hasegawa, Y. Synthesis of continuous silicon carbide fibre Part 5 Factors affecting stability of polycarbosilane to oxidation. J. Mater. Sci. 1986, 21, 4352-4358. [CrossRef] 
9. Wang, H.; Li, X.D.; Li, X.X.; Zhu, B.; Kim, D.P. The kinetics of oxidation curing of polycarbosilane fibers. Korean J. Chem. Eng. 2004, 21, 901-904. [CrossRef]

10. Ichikawa, H.; Teranishi, H.; Ishikawa, T. Effect of curing conditions on mechanical properties of SiC fibre (Nicalon). J. Mater. Sci. Lett. 1987, 6, 420-422. [CrossRef]

11. Peng, Z.; Hwang, J.; Mouris, J.; Hutcheon, R.; Huang, X. Microwave penetration depth in materials with non-zero magnetic susceptibility. ISIJ Int. 2010, 50, 1590-1596. [CrossRef]

12. Sugimoto, M.; Shimoo, T.; Okamura, K.; Seguchi, T. Reaction mechanisms of silicon carbide fiber synthesis by heat treatment of polycarbosilane fibers cured by radiation: II, free radical reaction. J. Am. Ceram. Soc. 1995, 78, 1849-1852. [CrossRef]

13. Narisawa, M.; Shimoda, M.; Okamura, K.; Sugimoto, M.; Seguchi, T. Reaction mechanism of the pyrolysis of polycarbosilane and polycarbosilazane as ceramic precursors. Bull. Chem. Soc. Jpn. 1995, 68, 1098-1104. [CrossRef]

14. Mao, X.H.; Song, Y.C.; Li, W.; Yang, D.X.; Si, À. Mechanism of curing process for polycarbosilane fiber with cyclohexene vapor. J. Appl. Polym. Sci. 2007, 105, 1651-1657. [CrossRef]

15. Hong, J.; Cho, K.Y.; Shin, D.G.; Kim, J.I.; Oh, S.T.; Riu, D.H. Low-temperature chemical vapour curing using iodine for fabrication of continuous silicon carbide fibres from low-molecular-weight polycarbosilane. J. Mater. Chem. A 2014, 2, 2781-2793. [CrossRef]

16. Hasegawa, Y. New curing method for polycarbosilane with unsaturaed hydrocarbons and application to thermally stable SiC fibre. Compos. Sci. Technol. 1994, 51, 161-166. [CrossRef]

17. Hong, J.S.; Cho, K.Y.; Shin, D.G.; Kim, J.I.; Riu, D.H. Iodine diffusion during iodine-vapor curing and its effects on the morphology of polycarbosilane/silicon carbide fibers. J. Appl. Polym. Sci. 2015, 132, 42687. [CrossRef]

18. Ishikawa, $\mathrm{T}$. Recent development of the $\mathrm{SiC}$ fiber nicalon and its composites, including properies of the SiC fiber Hi-Nicalon for ultra-high temperature. Compos. Sci. Technol. 1994, 51, 135-144. [CrossRef]

19. Cao, S.; Wang, J.; Wang, H. Formation mechanism of large SiC grains on SiC fiber surfaces during heat treatment. CrystEngComm 2016, 18, 3674-3682. [CrossRef]

20. Vijay, V.V.; Nair, S.G.; Sreejith, K.J.; Devasia, R. Synthesis, ceramic conversion and microstructure analysis of zirconium modified polycarbosilane. J. Inorg. Organomet. Polym. Mater. 2016, 26, 302-311. [CrossRef]

21. Ishikawa, T.; Kohtoku, Y.; Kumagawa, K.; Yamamura, T.; Nagasawa, T. High-strength alkali-resistant sintered SiCfibre stable to $2200{ }^{\circ} \mathrm{C}$. Nature 1998, 391, 773-775. [CrossRef]

22. Usukawa, R.; Ishikawa, T. High-performance SiC-polycrystalline fiber with smooth surface. Ceramics 2018, 1, 165-174. [CrossRef]

23. Ishikawa, T.; Oda, H. Defect control of SiC polycrystalline fiber synthesized from poly-aluminocarbosilane. J. Eur. Ceram. Soc. 2016, 36, 3657-3662. [CrossRef] 